\title{
Alterations of Acetylcholinesterase Activity and Antioxidant Capacity of Zebrafish Brain and Muscle Exposed to Sublethal Level of Cadmium
}

\author{
Abeer Ghazie A. Al-Sawafi and Yunjun Yan
}

\begin{abstract}
Water pollutants have a high potential risk for the population health. Protection from toxic impacts of water contaminants includes understanding the mechanism of low level toxicity and possible biological effect on people's health. $\mathrm{Cd}$ is one kind of conventional water contaminants which necessary to assess their potential negative effects. Zebrefish

(Danio rerio) is often used as animal model in bioassessment. In this study, the fish was respectively exposed to $1 / 15_{\text {th }}(0.636$ $\left.\mathrm{mg} \mathrm{L}^{-1}\right), 1 / 10_{\text {th }}\left(0.954 \mathrm{mg} \mathrm{L}^{-1}\right)$ and $1 / 5_{\text {th }}\left(1.908 \mathrm{mg} \mathrm{L}^{-1}\right)$ of the $\mathrm{LC}_{50}$ value, and the treatment was set for $5,10,15,20$ and 25 days. $A$ decrease in biomarkers of $\mathrm{AChE}$ activity with dose and time-dependent manner and significantly increased in activities of antioxidant enzymes catalase (CAT) and superoxide dismutase (SOD) in the brain and muscle of the fish when exposure to $\mathrm{Cd}$. Then, the treatment was reduced the amount of protein content. This indicates that sublethal concentration treatment of $C d$ can cause changes at various levels, such as inducing alterations in the enzyme engaging in the control of cholinergic transmission, arising antioxidant competence and reducing protein content of the different tissues, which suggests low-level Cd contaminant may bring serious potential health risk.
\end{abstract}

Index Terms-Cadmium toxicity, AChE activity, oxidative stress, Zebrafish.

\section{INTRODUCTION}

The past few decades, water environments are polluted with a variety of contaminants. Among the potential toxic water contaminants, heavy metals are considered as the most vindictive ones because of their ability to biomagnification in the aquatic food chains. $\mathrm{Cd}$, one of the conventional heavy metals is unnecessary and non-biodegradable [1]. Thus, it is a main contaminant of aquatic environments exerting devastating impact on the aquatic organisms, and its truly biological function is relatively less known [2]. It enters aquatic environments through paper, smoldering units, PVC plastic, mining, electroplating, pigments, ceramic industries, batteries and many other industrial processing. Also, it enters aquatic ecosystem through sewage sludge and agricultural runoff because it is one of the main constituents of phosphate fertilizer [3]. While a source of acute $\mathrm{Cd}$ pollution can

2013; revised March 4, 2013.

Abeer Ghazie A. Al-Sawafi is with the College of Life Science and Technology, Huazhong University of Science and Technology, Wuhan, Hubei, China. He is also with Foundation of Technical Education, Technical College, Environmental and Pollution Engineering Department, Basrah, Iraq (e-mail: abeerghazie@yahoo.com).

Yunjun Yan was with College of Life Science and Technology, Huazhong University of Science and Technology, Wuhan, Hubei, China (e-mail: yanyunjun@hust.edu.cn). happen from an accidental released from industrial wastewater, more important cases in the long-term pollution are logged when $\mathrm{Cd}$ is deposited in bottom sediments and then transferred to the food chain in the aquatic environment [4].

In the aquatic environment, fish plays an increasingly significant role in the monitoring water contamination because it responds with highly sensitivity for variations in the aquatic environment. Zebrafish is an ideal vertebrate model for studying multiple biological events, such as neurochemical alterations elicited by heavy metal toxicity [5]. Zebrafish presents a unique case among vertebrates, because $\mathrm{AChE}$ is the only ACh-hydrolyzing enzyme in this organism. In addition, AChE of zebrafish is highly related to that of mammals [6].

Recently, they have been extended to be forecasting models for chronic toxicity of long term tissue-specific metal scraps. For this reason, some authors confirmed that more researches are required concerning the effect of sublethal exposure to low toxic concentrations of fish. Therefore, the purpose of the present study was to investigate in vitro the sublethal effects of heavy metal $\mathrm{Cd}$ on AChE activity, antioxidant defenses and protein content in the brain and muscle tissues of an aquatic and well-established organism for toxicological analysis, zebrafish.

\section{MATERIAL AND METHODS}

Zebrafish (3.1 -4.6 cm in length, 0.295 to $0.847 \mathrm{~g}$ in weight) used as object for sublethal test was purchased from the Institute of hydrobiology, Chinese academy of Science, Wuhan, P. R. China. They were fed twice a day with commercial fish food. The cadmium stock solutions were prepared from $\mathrm{CdCl}_{2} \cdot 2.5 \mathrm{H}_{2} \mathrm{O}$ was prepared in deionized water. Fish samples were divided into four groups, each containing 100 fishes in an aquarium of 40-liter capacity. Group I was held in tap water as control and other groups were exposed to sublethal concentrations $1 / 15_{\text {th }}(0.636 \mathrm{mg}$ $\left.\mathrm{L}^{-1}\right), 1 / 10_{\text {th }}\left(0.954 \mathrm{mg} \mathrm{L}^{-1}\right)$ and $1 / 5_{\text {th }}\left(1.908 \mathrm{mg} \mathrm{L}^{-1}\right)$ of the $\mathrm{LC}_{50}$ value, for $5,10,15,20$ and 25 days. At the end of each exposure period, the fish were removed from each tank to dissect. Then, the required tissues were collected for biochemical analysis, after homogenized to $1 / 10(\mathrm{w} / \mathrm{v})$ ratio of cold physiological saline solution $\mathrm{NaCl}(0.86 \%)$ using a mortar and pestle, and then, centrifuged at $8000 \mathrm{r} / \mathrm{min}$ for 10 $\min$ in $4{ }^{\circ} \mathrm{C}$, the supernatant was used for biochemical analysis.

AChE activity was determined at $412 \mathrm{~nm}$ wavelength by 
method of [7]. Acetylcholine iodide and dithiobis nitrobenzoic acid were used as substrates. SOD and CAT activities were measured by method of [8]. The specific activity was defined as units of activity per milligram of protein. Total protein content was quantified by the procedure of reference [9] at $595 \mathrm{~nm}$ and using bovine serum albumin as standard. And the standard calibration curve was set as $y=0.0051 x-0.0013\left(R^{2}=0.9993\right)$.

The data obtained was analyzed statistically by two-way Analysis of variance (ANOVA). The differences between the control and the exposed groups were well checked. The criterion for significance was set at $p<0.05$. Statistical analysis was performed by GraphPad software.

\section{RESULT}

AChE activity in brain tissue of zebrafish was decreased significantly $(p<0.01)$ by $29.323 \%, 73.709 \%$ and $80.142 \%$, respectively, in response to 0.636 and $1.908 \mathrm{mg} \mathrm{L}^{-1} \mathrm{Cd}$ after 15 , 20, 25 days (Fig. 1).

With respect to the $0.954 \mathrm{mg} \mathrm{L}^{-1}$ exposure of $\mathrm{Cd}, 52.036 \%$ reduction of the AChE activity in brain was observed $(p<0.01)$ only after 15 days of treatment. In muscle, the maximum decrease of AChE activity by $54.281 \%, 48.594 \%$ and $32.456 \%$, respectively, after 5 days of treatment at all concentrations was detected $(p<0.05)$.
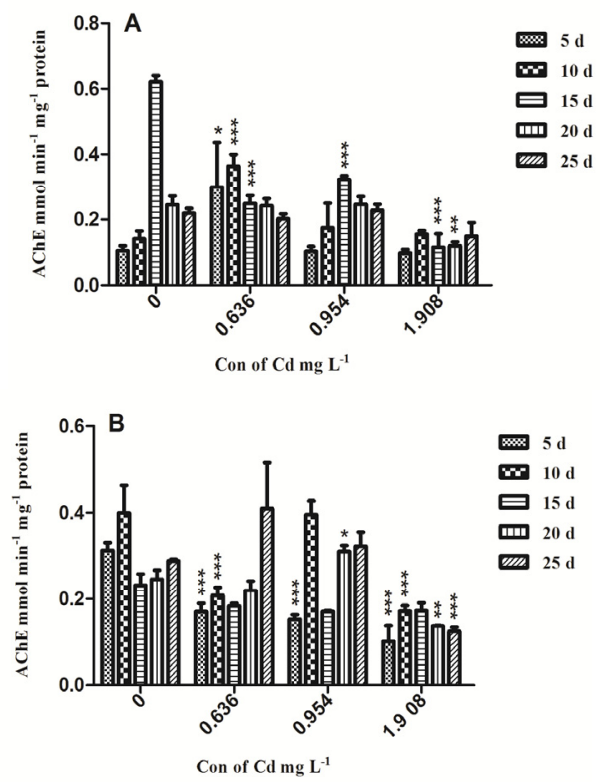

Fig. 1. AChE activities in (A) brain and (B) muscle tissues of zebrafish after exposure to different $\mathrm{Cd}$ concentration for 5, 10, 15, 20 and 25 days. The standard deviations values with different significantly compared to the control; * at $p<0.05, * *$ at $p<0.01$ and *** at $p<0.001$ levels.

In brain, the antioxidant SOD activity showed marked increase $(p<0.01)$ after 10,15 and 25 days of Cd treatment at 0.954 and $1.908 \mathrm{mg} \mathrm{L}^{-1}$ concentrations by $147.71 \%$, $216.85 \%$ and $177.44 \%$. Whereas, at $0.636 \mathrm{mg} \mathrm{L}^{-1}$, the enzyme activity increased by $165.188 \%$ after 25 days.

The activity of SOD in muscle increased significantly $(p<$ 0.01 ) after 25 days $\mathrm{Cd}$ trearment at all concentration by $145.39,143.32$ and $125.39 \%$, respectively, when compared with the control (Fig. 2).

Fig. 3 shows that the activity of the antioxidant enzymes CAT increased in a dose and time-dependent manner in muscle and brain tissues after 5, 10, 15, 20, 25 days. However, the effect was more prounced in brain in comparison to muscle. In brain, the activity showed markedly increased ( $\mathrm{p}<$ 0.01 ) after $10,15,20,25$ days of $\mathrm{Cd}$ treatment at all concentration by $176.73,227.39,193.34$ and $117.77 \%$, respectively, over control values.

Protein content mostly decreased in a dose and time-dependent manner after treatment for 5, 10, 15 and 20 days by $53.54,17.87,31.70$ and $41.49 \%$, respectively, at all concentration in brain (Fig. 4). While in muscle, protein content decreased after 10 days of $\mathrm{Cd}$ exposure at all tested concentrations. The decreases were 55.66, 69.82 and $68.29 \%$, respectively (Fig. 4).
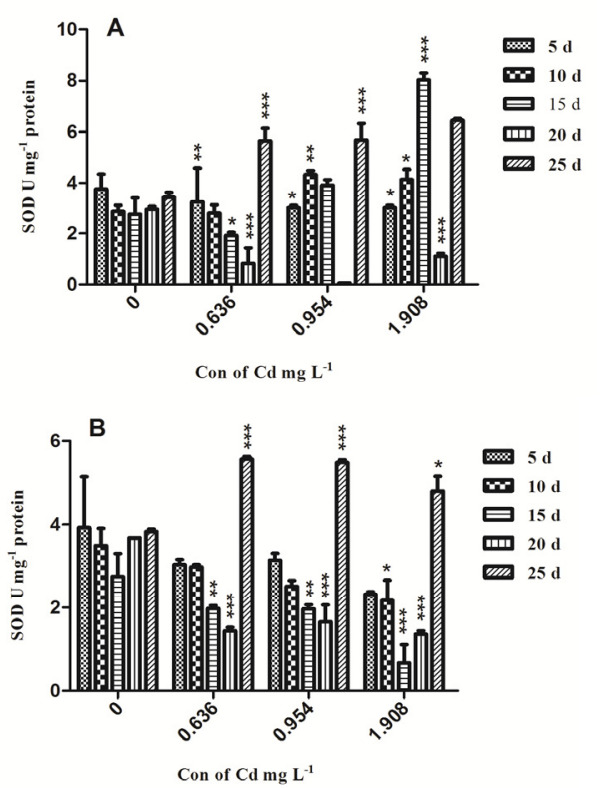

Fig. 2. SOD activities in (A)brain and (B)muscle tissues of zebrafish after exposure to different $\mathrm{Cd}$ concentration for $5,10,15,20$ and 25 days. The standard deviations values with different significantly compared to the control; * at $p<0.05, * *$ at $p<0.01$ and $* * *$ at $p<0.001$ levels.
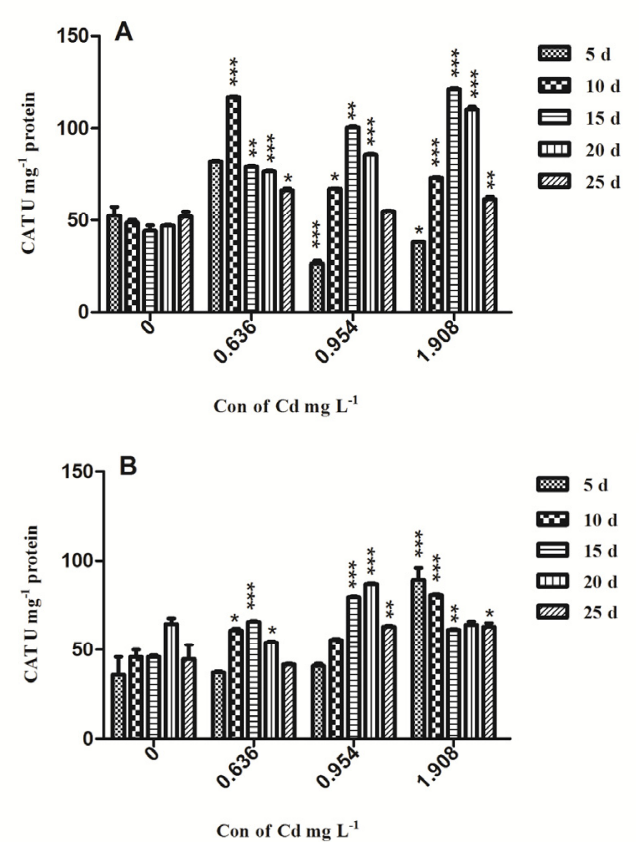

Fig. 3. CAT activities in (A) brain and (B) muscle tissues of zebrafish after exposure to different $\mathrm{Cd}$ concentration for 5, 10, 15, 20 and 25 days. The standard deviations values with different significantly compared to the control; * at $p<0.05, * *$ at $p<0.01$ and *** at $p<0.001$ levels. 

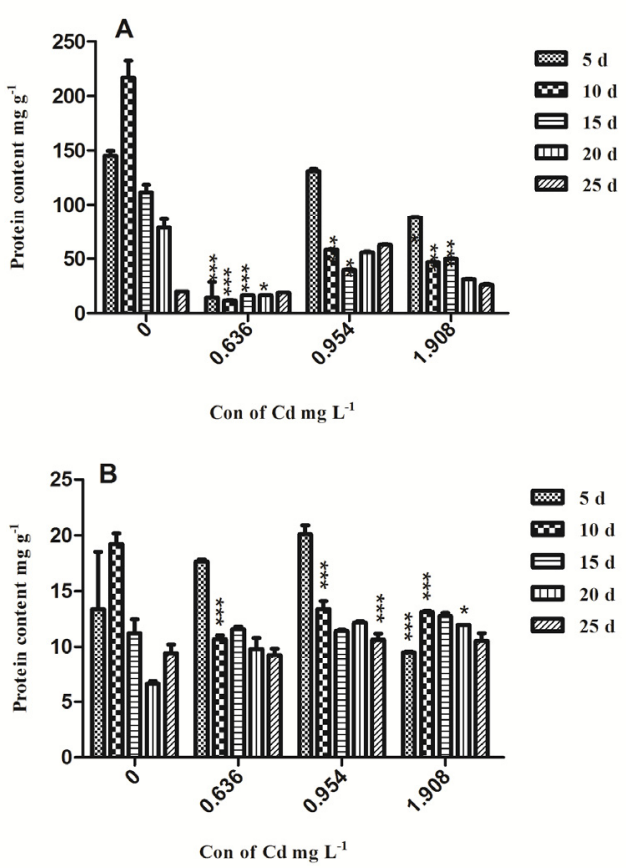

Fig. 4. Protein conteints in (A) brain and (B) muscle tissues of zebrafish after exposure to different $\mathrm{Cd}$ concentration for 5, 10, 15, 20 and 25 days. The standard deviations values with different significantly compared to the control; * at $p<0.05, * *$ at $p<0.01$ and $* * *$ at $p<0.001$ levels.

\section{DISCUSSION}

The present study, we have evaluated the effect of different sublethal treatments of $\mathrm{Cd}$ for a long duration time on the $\mathrm{AChE}$ activity and antioxidant competence in brain and muscle tissues of zebrafish. In addition, we have also shown the effects of the treatments on the protein content in zebrafish tissue. In ecotoxicology, biomarkers are often be used to measure the interaction between biological system and a chemical, physical or biological environmental agent. In vivo, inhibition or induction of biomarkers could be seen a good tool for evaluation exposure and possible impacts of xenobiotics on living organisms [10]. The results demonstrated a significant inhibition $(p<0.01$, Fig. 1) on AChE after sublethal treatment of $\mathrm{Cd}$ in brain and muscle of zebrafish. Consequently, it is possible to note that the exposure to low concentrations of these metals in the aquatic environment interferes with the acetylcholine hydrolysis differing with the time and level of exposure. The inhibition of esterase by minerals may be due to physiological variations in animals, which indirectly leads to decline in enzyme activity [5]. So, esterase is a good biomarker to distinguish between the levels of pollutants. In the present study, Cd significantly decreased AChE activity after sublethal exposure, similar to the previous report by reference [11], which demonstrated significant decrease in AChE activity of (Mugil cephalus) after sublethal exposure of cadmium, copper, lead and zinc, as well as of zebrafish exposure to copper, iron, lead and cadmium [5].

Antioxidants are very important in oxidative stress-related disorders and they act as therapeutic agents. A previous study has dealt with antioxidant systems in response to cadmium pollution. Oxidative stress is an important component of the stress response in aquatic organisms exposed to several insults as a result of alterations in environmental conditions such as contamination. The main antioxidant enzyme systems consist of superoxide dismutase (SOD), which detoxifies $\mathrm{O}_{2}{ }^{-}{ }^{-}$[1], catalase (CAT), which reduces $\mathrm{H}_{2} \mathrm{O}_{2}$ into water and oxygen [3]. The sublethal exposure to heavy metals stimulates the activities of antioxidant enzymes of different fish species. Alteration in antioxidant enzyme activities may be used as biomarkers for pollution in various aquatic organisms because antioxidant enzymes such as SOD, CAT provide the first line of cellular defense against toxic free radicals, which cause oxidative stress [12]. SOD catalyzes the destruction of superoxide radical by dismutation and $\mathrm{H}_{2} \mathrm{O}_{2}$ formation. Our results showed an increase in SOD and CAT activities following $\mathrm{Cd}$ stress in muscle and brain of zebrafish, but the increase was more pronounced in brain in a dose and time-dependent manner (Fig 2 and Fig 3). It indicates that a rise in the $\mathrm{O}_{2}{ }^{\cdot-}$ generation rate may occurred and the protective role of this enzyme against metal-induced oxidative stress acts. The increase in SOD activity for Cd-exposure would lead to in a higher generation of $\mathrm{H}_{2} \mathrm{O}_{2}$. However, the activity of CAT is responsible for detoxification of $\mathrm{H}_{2} \mathrm{O}_{2}$ into water. Similarly, chronic exposure to $\mathrm{Cd}$ increased SOD activity in muscle and liver of Nile tilapia (Oreochromis niloticus) [13]. After brown trout (Salmo trutta) was exposed to Cd for $15 \mathrm{~d}$, SOD activity increased in gill and liver, while CAT activity increased in gill but did not alter in liver tissues [1].

Proteins are important organic substances necessary for organisms in tissue building and play a significant role in energy metabolism [14]. The result of the present study showed significant decrease in protein content in the tissues studied (Fig 4 ). The percentage of decrease was found to be greater in all exposures in brain tissue. The reduction of protein may be a result of proteolysis and increases metabolism under toxicant stress. The result of the present study is similar to the report by reference [15], which indicated a depletion of protein in liver, gill and kidney of (Channa punctatus) when exposed to sublethal concentration $\left(0.36 \mathrm{mg} \mathrm{L}^{-1}\right)$ of copper sulphate for 15,30 and 45 days. In contrast, Almeida [13] observed there was no alteration in total protein content in white muscle of Nile tilapia (Oreochromis niloticus) with cadmium exposure, suggesting a metabolic shift of carbohydrate metabolism to maintenance of the muscle protein reserve.

\section{CONCLUSION}

So far, little is known about the real toxicity of heavy metals to aquatic organisms. Therefore, it is impossible to determine whether current water quality criteria are protective. As demonstrated that the heavy metal goals occur at various levels, such as including alterations in the enzyme engaged in the control of cholinergic transmission, in antioxidant competence and reduction of protein content, which may be a small part of the wide spectrum of actions elicited by these contaminants. Consequently, we suggest that our findings show a clear negative impact of $\mathrm{Cd}$ on AChE activities. Meanwhile, in environmental studies using esterase as specific biomarker of pollution by heavy metal cadmium, significant increases of antioxidants (CAT and SOD) were observed. So, we conclude that resistance development is linked with the increased activities of antioxidant enzymes, which are important in protecting organisms from cadmium damage..

\section{REFERENCES}

[1] B. H. Hansen, S. RØmma, Ø. A.Garmo, S. A.Pedersen, P. A. Olsvik, and R. A. Andersen, "Induction and activity of oxidative stress-related proteins during waterborne $\mathrm{Cd} / \mathrm{Zn}$-exposure in brown trout (Salmo trutta)," Chemosphere, vol. 67, pp. 2241-2249, Feb. 2007. 
[2] D. Kasherwani, H. S. Lodhi, K. Ji Tiwari, S. Shukla, and U.D. Sharma, "Cadmium Toxicity to Freshwater Catfish, Heteropneustes fossilis (Bloch)," Asian J. Exp. Sci., vol. 23, no. 1, pp.149-156, 2009.

[3] J. Dorts, A. Bauwin, P. Kestemont, S. Jolly, W. Sanchez, and F. Silvestre, "Proteasome and antioxidant responses in Cottus gobio during a combined exposure to heat stress and cadmium," Comparative Biochemistry and Physiology, Part C, vol. 155, pp. 318-324, Oct. 2012.

[4] J. Drastichová, Z. Svobodová, V. Lusková, and J. Máchova, "Effect of Cadmium on Hematological Indices of Common Carp (Cyprinus carpio L.)," Bull. Environ. Contam. Toxicol., vol. 72, pp. 725-732, Jan. 2004.

[5] D. de Lima, G. M. Roque, and E. A. de Almeida, "In vitro and in vivo inhibition of acetylcholinesterase and carboxylesterase by metals in zebrafish (Danio rerio)," Marine Environmental Research xxx, pp. 1-7, Nov. 2012.

[6] M. Behra, C. Etard, X. Cousin, and U. Strähle, "The Use of Zebrafish Mutants to Identify Secondary Target Effects of Acetylcholine Esterase Inhibitors," Toxicological Sciences, vol. 77, pp. 325-333, Oct. 2004.

[7] G. L. Ellman, k. D. Courtney, V. Andres, J R. and R. M. Featherstone, "A new and rapid colorimetric determination of acetylcholinesterase activity," Biochemical pharmacology, vol. 7, pp. 88-95, 1961.

[8] Z. Can, "Toxic effects of Butyl-Benzyl phthalate on Zebrafish and cloning, Expression of Acetylcholinesterase Gene," M.S. thesis, College of Life Science, Central Normal University, China, 2011.

[9] M. M. Bradford, "A rapid and sensitive assay of protein utilizing the principle of dye binding," Analytical Biochemistry, vol. 72, pp. 248-254, Jan. 1971.

[10] J. RendÓn-von Osten, A. Ortíz-Arana, L. Guilhermino, A. M. V. M. Soares, "In vivo evaluation of three biomarkers in the mosquitofish (Gambusia yucatana) exposed to pesticides," Chemosphere, vol. 58, pp. 627-636, Aug. 2005.

[11] J. S. I Rajkumar and M. C. J. Milton, "Biochemical markers of oxidative stress in mugil cephalus exposed to cadmium, copper, lead and zinc," International Journal of Pharma and Bio Sciences, vol. 2, Issue 3, pp. B41-B50, Jul.-Sep., 2011.

[12] M. M. Hegazi, Z. I. Attia, and O. A. Ashour, "Oxidative stress and antioxidant enzymes in liver and white muscle of Nile tilapia juveniles in chronic ammonia exposure," Aquatic Toxicology, vol. 99, pp. 118-125, April 2010

[13] J. A. Almeidaa, Y. S. Diniz, S. F. G. Marques, L. A. Faine, B. O. Ribas, R. C. Burneiko, and E. L. B. Novelli, "The use of the oxidative stress responses as biomarkers in Nile tilapia (Oreochromis niloticus) exposed to in vivo cadmium contamination," Environment International, vol. 27, pp. 673-679, Nov. 2002.

[14] M. A. Al-Kahtani, "Effect of an Insecticide Abamectin on Some Biochemical Characteristics of Tilapia Fish (Oreochromis Niloticus)," American Journal of Agricultural and Biological Sciences, vol. 6, no. 1, pp. 62-68, 2011.

[15] D. Singh, S. Katiyar, and A. Verma, "Role of Copper Sulphate on Oxidative and Metabolic Enzymes of Freshwater Fish; Channa Punctatus," J Environment Analytic Toxicol, vol. 2, Issue 1, 2012

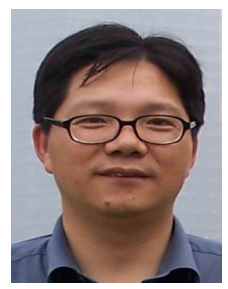

Yan Yunjun was born at Luotian County, Hubei Province, China, on September, 1969. He received B.S. in biology, Central China Normal University, Wuhan City in 1993 and M.S. in zoology, Central China Normal University, Wuhan City in 1995 . He was also Ph.D. in hydrobiology, Institute of Hydrobiology, the Chinese Academy of Sciences, Wuhan City, P. R. China, in 1998. In 2002 he is Professor of Biotechnology and from 2012 till Present) is Vice Dean of College of Life Sciences and Technology, College of Life Sciences and Technology, Huazhong University of Science and Technology; 1037, Luoyu Road, Hongshan District, Wuhan, China.

Prof. Yan is Senior committee member of the Chinese Society of Biological Engineering and Chinese Society of Microbiology. He holds a Second-grade Award from China Medical Association in 2009, and from Journal "Chinese Journal of Biotechnology" in 2009 and 2011.

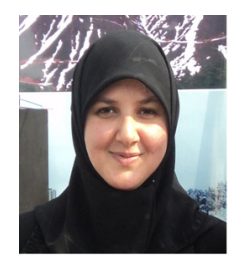

Abeer Ghazie A. Al-Sawafi was born at Basrah city, Iraq, on 6 June, 1978. She received B.S. in biology department, Science College, in 2000 and M.S. in Environmental pollution, biology department, Science College, Basrah University, Iraq, in 2005. Now, she is $\mathrm{Ph} . \mathrm{D}$. Candidate in College of Life Science and Technology, Huazhong University of Science and Technology, Wuhan, China. She is (2001-2013) a Lecturer in Environmental and Pollution Engineering Department, Technical College, Foundation of Technical Education, Iraq. 